\title{
A Comprehensive Strategy to Formulate Framework in Post-Kyoto Era
}

\author{
Arif Md. Waliullah Bhuiyan and Md. Rejwanur Rashid Mojumdar, Member, ICCSIT
}

\begin{abstract}
Two consecutive low-yielded attempts in Copenhagen and then in Cancun brought down any possibility to develop an effective post-Kyoto policy framework by the end of 2012. Obstinacy of USA, readily available AAUs in Europe and unsustainable energy generation in China, India or Brazil are some of the reasons why the world is still struggling to minimize overall GHG emission. To meet the interest of both emerging developing nations and developed nations without restricting anyone's potential economic growth and at the same time find an effective means to involve other under-developed countries are the biggest challenges for any post-Kyoto agreement. It should be flexible and attractive enough to involve developed, emerging and developing economy in order to seek opportunities for their own interest. This paper briefly discusses Kyoto protocol and Clean Development Mechanism (CDM) and then outlines 'a green strategy' which could effectively address the concerns of all stake holders and yet achieve reduction in emission.
\end{abstract}

\section{Index Terms-Climate change, Kyoto protocol, CDM}

\section{INTRODUCTION}

Kyoto Protocol, one of the most vibrant initiatives at global level, is coming to its closing date on 2012 and UNFCCC is still struggling to come up with a rational post-Kyoto framework that will resolve the economic tug-of-war between developed and developing countries. UNFCCC although insisted that developed countries should take the lead in combating climate change, "dangerous anthropogenic interference" cannot be avoided by developed countries acting alone. Even an eighty percent reduction of greenhouse gas (“GHG") emissions in all developed countries by 2050 would not achieve this objective without emissions reductions by rapidly industrializing and developing countries. All countries should commit to reduce collectively global emissions by at least sixty percent below the 1990 level by 2050 to avoid the most serious impacts of climate change [1].

This paper after a brief discussion on Kyoto Protocol and Clean Development Mechanism (CDM) reviews the pros and cons of the current CDM and outlines a strategic framework to set up a stage for negotiation between developed and developing nations with an ultimate target of worldwide GHGs reduction.

Manuscript received May 14, 2011

Arif Md. Waliullah Bhuiyan is with BRAC, Mohakhali, Dhaka, Bangladesh. (e-mail: bhuiyan.waliullah@gmail.com).

Md. Rejwanur Rashid Mojumdar is with AREVA T\&D Bangladesh, House No-15 (4th Floor), Road\#24 (CNW), Gulshan-2, Dhaka-1212, Bangladesh. (e-mail: md.rejwanur.rashid.mojumdar@gmail.com).

\section{Kyoto PRotocol: CDM PERSPECTIVE}

The Kyoto Protocol is an international agreement linked to the United Nations Framework Convention on Climate Change that was adopted at the 3rd Conference of the Parties (COP3) in 1997 and came into force on 15th February 2005. The protocol requires 37 industrialized countries, referred to as Annex I countries that have ratified the protocol to limit their greenhouse gas (GHG) emissions over the period 2008 to 2012 by an agreed amount of $5.2 \%$ relative to their emissions in 1990. One of the core principles in the Protocol is to protect the climatic system "for the benefit of present and future generations of humankind, on the basis of equity and in accordance with their common but differentiated responsibilities and respective capacities" (Article 3.1)

The two project mechanisms are Joint Implementation (JI), GHG emission reduction projects in Annex I countries, and the clean development mechanism (CDM), GHG emission reduction projects that are developed in non-Annex I countries. These three mechanisms are jointly referred to as the Kyoto mechanisms. Each Annex I country receives assigned amount units (AAUs) equivalent to their target emissions for the commitment period which are the instruments for emissions trading, supplemented by the certified emission reduction units (CERs) that are issued against the emission reductions from CDM projects [2].

Developing (non-Annex 1) countries, exempt from the Kyoto Protocol's binding limits, are able to participate in the global emissions market by hosting projects under the Clean Development Mechanism (CDM). It enabled developing nations to participate in the treaty by selling carbon credits, termed 'certified emissions reductions' (CERs) and measured in tons of CO2-equivalent, to countries with emissions commitments. These CERs are subject to a process of verification and certification by a UN accrediting body before issuance and sale. Unlike allowance trading, the CDM is a project-based approach, with new credits continuously being created as new projects are verified. It was intended from the beginning that the CDM would create sustainable development benefits for developing nations. Indeed the first statement in the Kyoto Protocol that defines the CDM says clearly, "the purpose of the Clean Development Mechanism shall be to assist Parties not included in Annex I in achieving sustainable development and in contributing to the ultimate objective of the Convention...” (KP 12.2), an ordering which gives clear priority by the negotiators to sustainable development [3]. 


\section{EMISSION TREND AND FUTURE CHALLENGE}

Carbon dioxide emissions are mainly generated in a fossil fuel based power plant which account for almost $75 \%$ of overall emissions. In developing economies, these are very significant due to the fact that these countries mainly use coal, oil and gas coal for power generation which shares the highest emission intensity. Hence any strategy to reduce GHG emissions has to be focused on power generation technology.

Developing economies like India and China aspire to grow at a rate in the range of 5-10\% per year. To maintain this trend, they need a huge additional power generation facility to be created to meet the requirements of this growth rate. They will largely use coal for generating this power as, under current environment of costs and obligations, it appears to be cheapest option for them but the most inefficient one.

Fig. 1 bellow clearly demonstrates the fiercely increasing trend in world carbon dioxide emission from coal combustion.

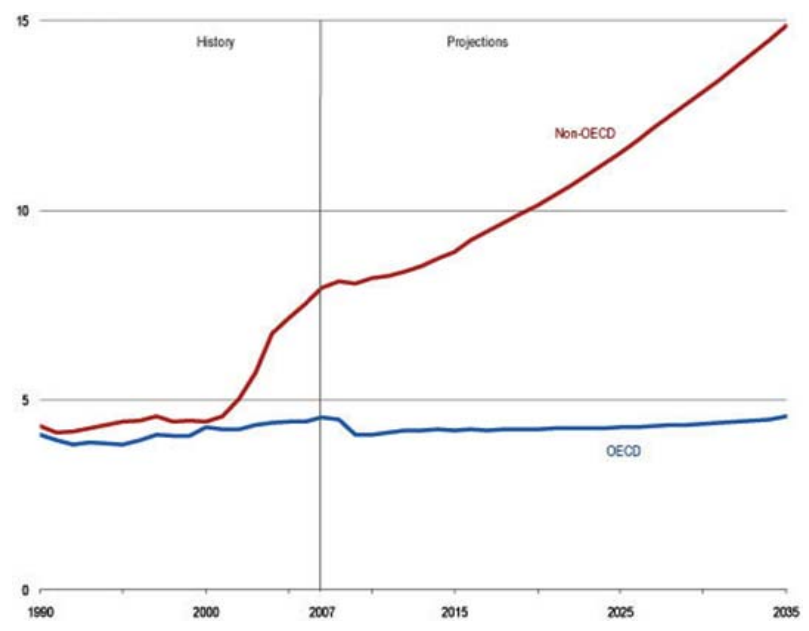

Fig. 1. World Carbon dioxide emission from coal combustion, 1990-2035 (billion metric tons) [4]

In such a scenario, the additional emissions from developing economies will far exceed the emissions reductions to be achieved by developing economies even if very aggressive targets are set for them. Reduction in $\mathrm{CO} 2$ emissions from an existing economic activity is not possible overnight and it needs a well thought long term strategy.

There are four possible strategies of reducing $\mathrm{CO} 2$ emissions from an economy:

a. Reduce absolute level of energy consumption for a given level of economic activity i.e. improve energy efficiency

b. Change energy-mix to increase share of cleaner fuel like gas as well as share of non-fossil based energy

c. Capture CO2 at major emitting centers and inject it back into earth for a possible application

d. Afforestation to provide natural sink for emissions [5]

Afforestation strategy posed some disadvantages as to sequester 1 million ton of carbon dioxide it requires to put about 100,000 hectares of area under plantation. So does sequestration technology and underground storage, although they are under intense study but as of now its cost effectiveness and sustainability are not established beyond doubt.

Considering the other options of energy efficiency and fuel switch at stake, it is possible to adopt these strategies by leveraging the CDM mechanism to fund part of the costs related to these measures and thereby maintaining the international competitiveness of the economic activities in developing economies. This mechanism is working well so far now and needs to be continued to encourage various measures of energy efficiency and fuel switch.

However, the challenge of ensuring total emissions below current levels despite rapid growth of developing economies can be handled only if non-fossil based power generation technologies are to contribute in a significant way for creation of additional power generation capacity in developing economies. Otherwise, only emission reduction obligation on developed countries even if they maintain acutely would not be sufficient enough to ensure overall global recession in GHGs.

\section{IMPLICATION ON CDM AFTER 2012}

Although CDM is the most efficient mechanism to bridge developing or under-developed countries with industrialized countries, complex bureaucratic application and rigorous verification process, available convenient option (buy unused AAUs) and high initial investment cost make it impotent.

Initial projects have been limited to a few countries and continue the similar trend for the projects in the pipeline. Through the mechanism only few tons of gases have been abated with little contribution to sustainable development.

Six years into the implementation of the early CDM projects, the mechanism is still viewed as an imperfect and immature approach to encourage the development of emissions-reduction projects in developing countries. However, many questions have been raised about the inequitable distribution of projects across developing world.

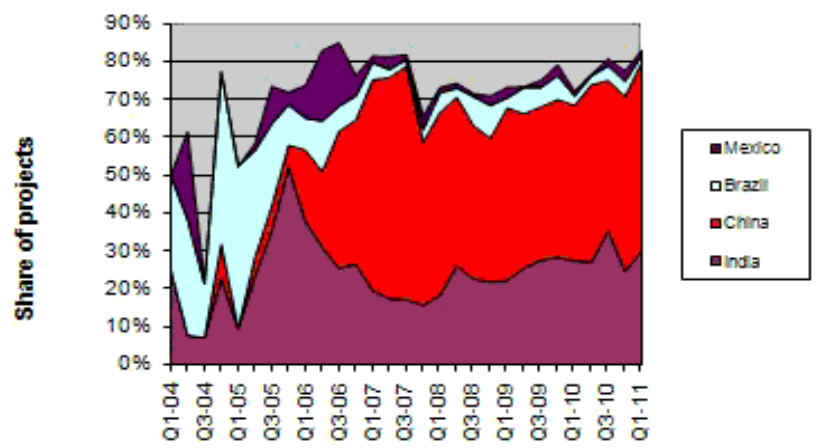

Fig. 2. All CDM Projects in the Pipeline in Brazil, Mexico, India, China as a fraction of all projects. Source: UNEP Risø Centre

For example, China is the world's second largest greenhouse gas emitter after the US. Nevertheless, it has received much of the carbon finance and accounted for $73 \%$ of transacted CER volume in 2007, due to relatively low cost of emissions abatement in China (World Bank, 2008). On the other hand, sub-Saharan Africa has gained little from technology transfer from the CDM to kick start development activities, hosting only $1.4 \%$ of CDM projects [3]. Fig. 2 shows the dominance of China and India in CDM as both of 
them account for almost 80\% of total CDM projects in 2011.

Under this context, the CDM should be reformed in order to deliver its full potential during the 2008-2012 commitment period, and in the post-2012 regime an additional market mechanism should support sectoral approaches capable of transforming whole sectors of rapidly industrializing countries at a speed commensurate with the challenge of taking emissions reductions to global scale. The CDM's weaknesses exist because it was created as a project-based instrument; however, the Executive Board recently approved the inclusion of "programmes of activities" in the CDM [6].

So far the CDM and JI help leverage capital for underlying climate investments, the extent to which they continue to do so is hampered by the market's uncertainty beyond 2012 . Credits are generated from the time the project is registered; losses due to delays in reaching registration cannot easily be recuperated by later vintages. In recent years analysts have steadily revised downward their projections for CER supply, which now range from 0.91 to 1.09 billion CERS issued by 2012, or, 1.03 billion CERs on average [7].

Multiple factors including smaller size of recent projects, growing delays on registration and issuance, increasing difficulty in securing finance, lack of clarity on the post-2012 have pushed down the expected flow of new projects. Delays and uncertainties lead to higher transaction costs, losses in CER volumes, and lower market values, diminishing the interest of potential project sponsors over the long term.
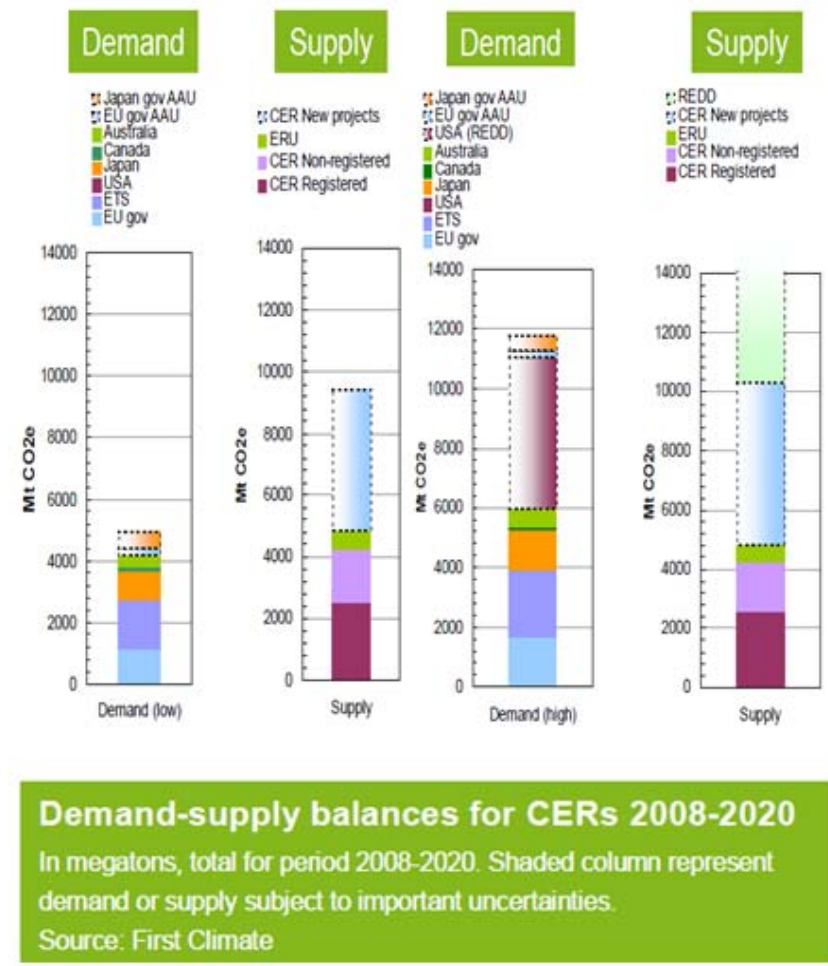

Fig. 3. Demand-supply balance for CERs for low and high demand projection [8] p-16,17

Fig. 3 illustrates two scenarios after 2012. If no satisfactory international agreement will reach that would lower annual growth of issuance for new projects as the demand falls. On the other hand, an agreement would set the tune so that vintages beyond 2012 will not face a lower demand with associated price implications.

\section{Suggested Strategy}

The intention of developed economies including USA have always indicated that they are willing to provide financial and technical support to developing economies if they are willing to adopt emission reduction measures with respect to business as usual. CDM is one of the most effective mechanisms under Kyoto Protocol to do this. The whole argument during Kyoto timeline comes down to international market dominance and raises the question that when whole developed world are moving towards cleaner technology is it justified to let developing economics to use less efficient measures of production.

It is necessary that the post-Kyoto framework should not be based on reduction percentages, but rather it should center on taking responsibility for the actual quantity of emissions.

The framework that would be adopted post-Kyoto should be flexible and attractive enough to involve both developed and developing economy in order to seek opportunities for their own interest.

a. Each economy based on their GDP and other development indicators have to restrict their cumulative power generation or consumption up-to a certain stage. And a major portion of that increased power generation must come from renewable sources.

b. Instead of setting one base year for the whole world, put different base years for different regions based on their history of industrialization.

c. Setting cap for both developing and developed countries with a strict power generation limit for the former and less strict for the later only if certain percentage of their total added power comes from renewable sources.

d. Per capita allocation would be more effective in GHG reduction and also leverage more fund flow from developed countries to least and developing countries.

e. Establish a strong and dynamic CDM; put it at the center of negotiation between developed and developing economies by making it more simple and affordable for smaller industries to get maximum benefit out of it.

f. Low coverage (the percentage of emissions of the countries bound to reduce emissions is low among total global emissions) and low efficiency (carbon leakage from the transfer of industries from countries engaged in reduction activities to countries that are not) as problems with the Kyoto Protocol, and emphasizes the importance of a framework where major greenhouse gas emitters such as the US, China and India would participate in reduction programs. Only with these countries' involvement, it would be possible to resolve the problems of coverage and poor efficiency. Participation from these countries in a post-Kyoto framework would require that the framework be flexible and consider the situation of each individual country [9].

g. Promote equal and equitable project distribution across region by mobilizing more and easy access to funds to under-developed regions.

h. Put especial attention to Africa; due to the nature of the political situation and capacity to develop infrastructure on large scale, it is suggested that small-scale projects like solar home systems (SHSs), solar cooker, solar irrigation pump etc. projects are more suitable for this region. 
However, in post-2012 regime if developed economies agree to fund to develop renewable energy technologies, particularly solar power projects in developing economies, in a manner where solar power becomes competitive with fossil fuel based power, everybody would have a win-win situation and an agreement could be reached whereby overall emission cap can be achieved.

It is felt that the developed economies should commit funds to ensure creation of about 300,000 MW of solar power generation capacity by 2020 in developing economies. In this manner, developing economies will have no objections to commit to add capacity for power generation mainly (say not less than $80 \%$ of total addition) on the non-fossil fuel based technologies as the competitiveness of their economies will not be affected [5].

\section{CDM As A ToOL FOR NEGOtiATION AT POST-KyOtO}

The CDM is seen by many as a pioneer instrument towards the green-path of sustainability. It is regarded as the first global, environmental investment and credit scheme of its kind, providing a standardized emission offset instrument, CERs. The mechanism encourages sustainable development and stimulates emission reductions with some flexibility for the industrialized countries to choose various options to meet their emission reduction or limitation targets. But the CDM market forced to take downstream due to world economic recession and availability of large AAUs in the market.

While in 2007 the average project needed 316 days to move from registration to first issuance, that time lengthened to 505 days in 2008 and to 607 days in 2009, for a total increase of $92 \%$ over two years. During the same period, the time required for projects to reach registration raised significantly less, from 373 days in 2007 to 572 days in 2009, an increase of 53\% [7].

To minimize this procrastination, concept of materiality in the clean development mechanism has been introduced in COP 15. This concept has been proposed to streamline CDM procedures and improved efficiency. The introduction of materiality is expected to reduce transaction costs by focusing the assessment of CDM project activities on issues that can have a larger impact on the estimation of their GHG emission reductions. It could help reduce the number of requests for review and avoid unnecessary delays in the CDM process [10]. Work has been undertaken by the Executive Board to adopt and apply revised procedures for the registration of project activities and the issuance of certified emission reductions, together with the revised procedures for review by the Executive Board of requests for registration and issuance of certified emission reductions [11].

The 'hot air' produced by legally bounded EU countries is one of the major reasons why CDM is unable to make a significant difference in GHG emission. Eastern EU Countries sell their AAUs to other developed EU countries, leaving CDM projects less attractive and secondary option for buying permit to emit more. As Fig. 4 shows potential supplies of Eastern EU and some other countries, it is obvious that other EU countries' demand will be met from those. On the other hand, although CDM and JI have enough
CERs, but due to bureaucratic procrastination those will not be availed by the demand side. That's why country wise emission profile instead of regional profile is more important. A major portion of current market is EU ETS whereas it should be CDM as long as the world leaders truly want the emission rate to come down.

\begin{tabular}{|c|c|c|c|c|}
\hline \multicolumn{2}{|c|}{$\begin{array}{l}\text { Potential Demand from } \\
\text { Industriallzed Countrles }(\mathrm{MtC} C \mathrm{C})\end{array}$} & \multirow{2}{*}{\multicolumn{3}{|c|}{$\begin{array}{l}\text { Potential Supplies } \\
\text { (MtCO,e) }\end{array}$}} \\
\hline \multirow{2}{*}{$\begin{array}{l}\text { Country or entity } \\
\text { EU }\end{array}$} & \multirow{2}{*}{$\begin{array}{c}\text { Kyoto assets demand } \\
690\end{array}$} & & & \\
\hline & & Potential GIS & $x, 800^{\prime}$ & \\
\hline Govemment (EU-15) & 350 & Russian Federation & 100 & \\
\hline Private sector (EU ETS) & 540 & Ukraine & $400-500$ & \\
\hline Japan & 300 & Eastern EU & 1325 & \\
\hline Govemment of Japan & 100 & & & \\
\hline Japanese private sector & 200 & & & \\
\hline Rest of Annex B & 32 & CDM \& J & 1,225 & range: $1,155-1,290$ \\
\hline Government & 25 & $\mathrm{CDM}$ & 1.030 & $975-1,085$ \\
\hline Private sector & 7 & $\mathrm{~J}$ & 195 & $180-205$ \\
\hline TOTAL & 1,222 & & & \\
\hline Government & 475 & & & \\
\hline Private sector & 747 & & & \\
\hline
\end{tabular}

Fig. 4. Supply-demand future for koyoto market [7] p-57

With buyers seeking sizeable and predictable volumes at attractive prices, the AAU market grew more than seven-fold in 2009 to US\$2.0 billion on $155 \mathrm{MtCO}_{2} \mathrm{e}$ transacted. Several countries have made significant progress in implementing Green Investment Schemes (GIS), and the potential has grown to 1,800 million AAUs (50\% of the total comes from Ukraine and Poland), which is much larger than the anticipated demand [7]. Since there is sufficient supply of available allowance, different entities can easily purchase on demand when emission exceed their free allocation. This would lead to negative effect on market dynamics and further lower the demand for CDM.

As the key criterion for eligibility as a CDM project is that the emission reductions are additional to those that would have occurred in the absence of the project activity, to keep the economy of both developing and developed countries on their current track, it seems CDM on a greater scale is the viable solution to post-Kyoto negotiation. A further important criterion for CDM is that the project must help the host developing country to achieve its sustainable development goals. The project must also satisfy any other criteria established by the host country government.

EU ETS is holding the driving position in carbon trading market due to easy transaction between countries. But as proposed, instead of region-wise allocation if country based allocation and capping limit is set then CDM will be more active. Although, in reality, country-wise allocation for European Union is less probable, unless the EU leaders are convinced that reformed policy of EU ETS in competitive CDM market can eventually enjoy more economic growth. Another more likely approach, as discussed earlier, is to put different base years for different regions based on their history of industrialization. By adopting any of these two, the relatively lesser developed countries of EU then have to deal with their own allocation and cap limit, instead of enjoying profit from 'hot air'. According to Hamasaki and Okagawa (2005), the carbon leakage rate of the US and Europe pulling out of the Kyoto Protocol is 56.3\% (2010). In other words, this shows that roughly half of the emission reduction in countries with reduction obligation is increased in countries 
with no such obligations [9].

CDM, with reinforced trait in pre-2013, has the opportunity to address these issues.

CERs increase the pool of credits available to Annex I countries for compliance with their Kyoto commitments. Ownership of the CERs is subject to negotiation between the project investors and the host project developers. The project developer may decide to sell their CERs forward in return for capital to fund the project's development, or retain rights to the CERs and sell them on the spot market at some future date.

\section{RENEWABLE ENERGY AS STRATEGIC SOLUTION}

Developments in renewable energy technologies have been quite rapid and very encouraging. Renewable energy sources are available in abundance and helps in generating power without little or no emissions. Hence, if a mechanism can be developed to ensure the current growth trend of developing economies and at the same time abating measurement to reduce per capita emission reduction for developed countries without putting much stress on their GDP then the target of capping total global emissions can be achieved.

However, economics of some of the 'clean options' especially solar power are currently not competitive enough with respect to power generating options and any strategy planned to use renewable energy needs to find a mechanism to address this constraint. Study has shown that Stand Alone Photo-Voltaic (SAPV), most simple solar application, has the potential to address the sustainable development of a country by putting no stress on current growth rate.

A study held in India on SAPV backed up the statement above. According to the study, in India, only through SAPV system to ensure access to electricity for all families' carbon dioxide emission reduction is $95.33 \times 10^{6}$ tons/annum. Total electricity produced by these SAPV panels: $102.287 \times 10^{6}$ MWh/annum = 9057.77 million/annum.

Total Carbon Credit earned =1910 million/annum [12]

Small CDM projects do not requires high engineering technologies that have to adopt from developed countries. Small scale renewable projects often enjoy several advantages which enables them to work in less advanced environment like in African or south-Asian countries. Projects generating less than 15000 CERs per annum are exempt from the fee. In addition, CDM projects in all but the least developed countries are subject to a levy ( $2 \%$ of the value of the credits that accrue) payable into an 'adaptation fund' to assist countries to adapt to the impacts of Climate Change [2].

Simplified procedures have been developed for small-scale projects to reduce the burden on the project developer and facilitate a faster implementation of the project.

Small scale projects, inter alia, are:

a. Renewable energy projects with a maximum capacity of 15MW

b. Energy efficiency projects that reduce energy consumption by less than 60GWh per year

c. Other projects that emit less than 60ktonne CO2 annually d. Small-scale a forestation and reforestation projects removing up to 16 Ktonnes of CO2 annually

\begin{tabular}{|c|c|c|c|c|}
\hline $\begin{array}{c}\text { Example } \\
\text { Technology } \\
\text { Application }\end{array}$ & $\begin{array}{c}\text { System } \\
\text { Capacity }\end{array}$ & $\begin{array}{c}\text { Example } \\
\text { System Cost }\end{array}$ & $\begin{array}{c}\text { Example tCO } \\
\text { Reduced/Yr. }\end{array}$ & $\begin{array}{c}\text { Gross Carbon } \\
\text { Revenue as \% } \\
\text { of System Cost }\end{array}$ \\
\hline $\begin{array}{c}\text { PV Home Lighting, } \\
\text { Central America }\end{array}$ & $35 \mathrm{Wp}$ & $\$ 500$ & 0.36 & $5 \%$ \\
\hline $\begin{array}{c}\text { Wind Power, South } \\
\text { America }\end{array}$ & $2 \mathrm{MW}$ & $\$ 2,500,000$ & 7,200 & $22 \%$ \\
\hline $\begin{array}{c}\text { Solar Water } \\
\text { Heating, South Asia }\end{array}$ & $1.4 \mathrm{kWth}$ & $\$ 350$ & 1.5 & $32 \%$ \\
\hline $\begin{array}{c}\text { Micro-hydro Power, } \\
\text { Southeast Asia }\end{array}$ & $15 \mathrm{~kW}$ & $\$ 27,500$ & 218 & $59 \%$ \\
\hline $\begin{array}{c}\text { Biogas Stove, } \\
\text { South Asia }\end{array}$ & Residential & $\$ 300$ & 4.9 & $123 \%$ \\
\hline $\begin{array}{c}\text { Efficient Wood } \\
\text { Stove, East Africa }\end{array}$ & Residential & $\$ 10$ & 2.5 & $469 \%{ }^{* *}$ \\
\hline
\end{tabular}

Fig. 5. Revenue potential for different renewable energy projects [13] p-15

As depicted in fig. 5, some of the small-scale renewable projects has higher rate of return those can be adopted by developing or least developed countries to ensure their flow of fund from developed economies as their consumption rate is unlikely to decrease in near future. Once sufficient fund is managed then these countries could afford to move to higher technology.

\section{MEChANISM FOR FUnd MOBILIZATION}

Finance is a critical element of any strategy to address climate change effectively. Funds will be required for increased assistance to developing countries for the adoption of energy efficiency and clean energy technologies, and for avoided deforestation. Funds will be required for greening power sectors, for adaptation, and for increased R\&D and deployment in all countries, focusing especially on technologies that are technically viable but not yet financially competitive [1].

As most investments in global economy are made by corporations (60\%) with the balance being made by households (26\%) and governments (14\%) [14], decentralization of fund mobilization through multinational private companies, banks and other financial institutes will be more dynamic and effective rather than UN-based or country specific donations. So if the private sector comes into the picture to invest in clean energy initiatives that will create a competitive market. Creation of such a large market will develop pressures in the global market to develop more efficient technologies to reduce costs. This will ensure renewable technologies especially solar energy to be competitive with respect to fossil fuel based power generation by 2020. With this specific financing package like one proposed in this strategy future developments will be possible without any serious threat of increase in concentration of GHGs in environment.

Developed economies should also contribute by creating a noteworthy corpus of funds, for a period of 10 years from 2011 to 2020, in proportion to their absolute emissions in the base year. The funds could be managed through a special window of a multilateral institution like World Bank/ IMF etc. Strict monitoring and real time evaluation need to be adopted for CDM projects prior mobilizing fund.

At COP 16 held in Cancun, Mexico, the COP adopted 
decision through which it decided to establish a Green Climate Fund, to be designated as an operating entity of the financial mechanism of the Convention under Article 11, with arrangements to be concluded between the COP and the Green Climate Fund to ensure that it is accountable to and functions under the guidance of the COP. The newly created Green Climate Fund will support projects, programs, policies and other activities in developing country parties. Fund mobilization initiatives like this, beside GEF's adaptation and mitigation fund, will also ensure future sustainability of environment.

\section{CONCLUSION}

It is beyond doubt that market-based mechanisms are good at identifying the cheapest mitigation opportunities amongst existing options, and spurring innovations that have immediate cost reductions, but are less helpful in encouraging the development of new low emission technologies. Innovation targets to bring new, more efficient, and less costly technologies to market could be very helpful. Incentives could be provided to countries (and businesses) that beat these targets in the form of credits against their future emission targets [6].

The renewable energy industry globally will get a huge boost with better technological advancement through direct involvement of open market mechanism. And steady increase of oil price, awareness among mass population will eventually increases the demand of renewable technologies which will help this sector to rapidly achieve economies of scale and thereby able to compete with conventional power generation methods.

This proposed strategy, if needed with some modifications, can attain the requirements of both developed and developing economies and activate all stakeholders in an inter-active market mechanism.

\section{REFERENCES}

[1] Mohamed T. "Overview: Framework for a Post-Kyoto Climate Change Agreement," Sustainable Development Law \& Policy, vol. 8, issue 2, article 3, pp. 2-5, 2008

[2] Climate Change Projects Office (CCPO), BERR, A BEGINNNERS'S GUIDE TO THE CLEAN DEVELOPMENT MECHANISM, A Climate Change Projects Office Guide in association with Department for Environment, Food and Rural Affairs, 2008, UK, http://www.bis.gov.uk/files/file46702.pdf
[3] Boyd, E., et al.., "Reforming the CDM for sustainable development lessons learned and policy futures," Environmental Science \& Policy, vol. 12, Issue 7, pp. 820-831, November 2009

[4] International Energy Statistics database, EIA, 2010

[5] Ethical Energy-Petrochem Strategies Pvt. Ltd., Strategy for Post 2012 Kyoto Protocol Agreement, Ahmedabad, India, 2009

[6] Meckling, Jonas O; Chung, Gu Yoon "Sectoral approaches for a post-2012 climate regime: a taxonomy." Climate Policy, volume 9, number 6, pp. 652-668(17), 2009

[7] World Bank, State and Trend of the Carbon Market, Washington DC, 2010

[8] First Climate, Future of CDM Post 2012: A Buyer's Perspective, 2010

[9] H. Hamasaki, "Carbon Leakage and a Post-Kyoto Framework", Research Paper No.287, Fujitsu Research Institute (FRI), Japan, 2007

[10] Materiality standard under the Clean Development Mechanism, Technical paper, UNFCCC, 2011

[11] Report of the Conference of the Parties serving as the meeting of the Parties to the Kyoto Protocol on its sixth session, held in Cancun from 29 November to 10 December 2010, UNFCCC, 2011

[12] Prabhakant and Tiwari G. N., Evaluation of carbon credits earned by energy security in India, Center for Energy Studies, Indian Institute of Technology Delhi, Haus Khas, New Delhi 1100 16, India, ,2009

[13] Green market International, The Voluntary Carbon market: Status and Potential to Advance Sustainable Energy Alternatives, USA, 2007

[14] Erik Haites, Margaree Consultants, Inc. Toronto, Negotiations on additional investment \& financial flows to address climate change in developing countries, UNDP, July 2008.

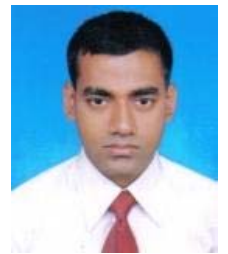

Arif Md. Waliullah Bhuiyan was born on 1986 in Mymensingh, Bangladesh. He completed his Bachelor of Science on Electrical and Electronic Engineering (EEE) in 2008 form Islamic University of Technology (IUT), Dhaka, Bangladesh. Currently he is working in Disaster, Environment \& Climate Change (DECC) and Water, Sanitation \& Hygiene (WASH) Programme as a Young Professional in BRAC, the largest non-government organization in the world. He works on disaster risk reduction, environmental degradation and different climate change issues through innovative newer suitable technologies for Bangladesh. His research interests include renewable and smart grid technologies, national and international environmental policies, micro issues of climate change. He is a member of IACSIT.

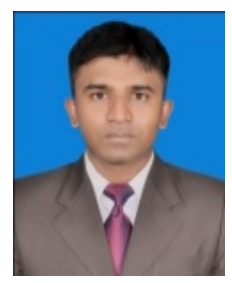

Md. Rejwanur Rashid Mojumdar was born in Dhaka, Bangladesh in 1986. He completed his Bachelor of Science on Electrical and Electronic Engineering (EEE) from the Islamic University of Technology (IUT), Bangladesh in November 2008. Since April 2009 to April 2011, he had worked as site engineer at NLDC (National Load Dispatch Centre) Project of AREVA T\&D Bangladesh. Currently he is working as energy auditor of HM Enviro Care in ESIP (Energy Saving Initiative Project) on the Program of PSES with cooperation of Deutsche GIZ GmbH. His research interests are renewable energy technologies, control systems, SCADA systems and smart grid technologies. He is a member of IACSIT. 